\title{
HOME CARE DALAM PERAWATAN ULKUS DIABETIKUM DI KOTA SEMARANG
}

\author{
Home Care in Ulcus Diabeticum Care in Semarang City
}

\author{
Eni Kusyati, Arista Adityasari Putri \\ STIKES Karya Husada Semarang \\ Email: enykusmiran@gmail.com
}

\begin{abstract}
ABSTRAK
Pendahuluan. Meningkatnya jumlah penderita Diabetes Mellitus menyebabkan peningkatan kejadian komplikasi diabetes, diantaranya luka pada kaki. Praktek keperawatan dapat berupa klinik ataupun perawatan di rumah (home care). Tujuan penelitian adalah memperoleh gambaran keputusan memilih perawat praktek mandiri melalui home care dalam perawatan ulcus diabeticum di kota Semarang. Metode. Metode penelitian kualitatif dilakukan pada 6 orang penderita Ulkus Diabetikum sebagai responden primer menggunakan Focus Group Discussion. Partisipan dipilih secara purposive sampling. Triangulasi sumber oleh praktisi praktek mandiri perawat dan ketua PPNI. Analisis data menggunakan content analysis thematic. Hasil. Hasil penelitian penyebab terjadinya luka juga menentukan waktu penyembuhan, perawatan luka yang baik dipahami lebih ke arah prosedur dan sifat empati yang menonjol dari perawat, partisipan mengetahui adanya praktek mandiri perawat dari membaca informasi papan praktek yang terpasang dan informasi dari orang lain, home care dipahami dari arti kalimat saja, sedangkan alasan dan keputusan menggunakan jasa home care karena banyak keuntungan yang diperoleh. Diskusi. Tanggapan yang positif dari masyarakat pengguna pelayanan home care karena perawat memiliki pengetahuan, keterampilan dan sikap yang sesuai dengan kebutuhan stake holder serta melakukan pelayanan secara komprehensif.
\end{abstract}

Kata kunci: Perawat praktek mandiri, Home care, Ulcus diabeticum

\begin{abstract}
Introduction. The increasing number of people with Diabetes Mellitus led to the incidence increase of diabetes complications, including foot ulcers. Nursing practice can be either in clinic or home care. The purpose of this research was to obtain the description of decision in selecting an independent nurse practice through home care in the treatment of ulcer diabeticum in Semarang. Methods. The research method used qualitative research conducted on 6 patients with Diabetic Ulcers as a primary respondent using Focus Group Discussion. The participants were selected by purposive sampling. Triangulation was obtained from independent nurse practitioners and the chairman of PPNI. The data analysis was done by using thematic content analysis. Results. The result of research showed that the cause of the injury also determined the period of healing, good wound cares were well understood more towards procedures and the nature of empathy that stood out from the nurses, the participants were aware of any independent nurse practices from reading the information board and knew the information from others, home care was understood from the meaning of sentences, while the reasons and the decision to use home care services because many advantages could be obtained. Discussion. There were positive responses from the community as home care services users that nurses had good knowledge, skills and attitudes that met the needs of stakeholders and could conduct comprehensive services.
\end{abstract}

Keywords: independent nurse practice, home care, and ulcer diabeticum

\section{PENDAHULUAN}

Prevalensi DM di Indonesia beranjak naik dari tahun ke tahun. Penderita yang terkena bukan hanya berusia tua, namun banyak pula yang masih berusia produktif. Prevalensi DM pada perempuan cenderung lebih tinggi dari pada laki-laki, di perkotaan cenderung lebih tinggi dari pada di perdesaan, serta cenderung lebih tinggi pada masyarakat dengan tingkat pendidikan tinggi (Kemenkes, 2013). Di Amerika Serikat sekitar 2,5\% dari penderita diabetes mellitus berkembang timbulnya luka kaki diabetes per tahun dan $15 \%$ dari penderita luka kaki diabetes yang akhirnya menjalani amputasi.

Menurut laporan International Diabetes Federation sebanyak 382 juta penduduk di seluruh dunia menderita Diabetes Mellitus (DM) dan akan terus bertambah setiap tahunnya. Kematian akibat diabetes angkanya pun cukup tinggi yaitu 5,1 juta jiwa pada tahun 2013. Indonesia sendiri menempati posisi ke-7 dengan jumlah penderita diabetes dalam rentang usia 20-79 tahun yang berjumlah 8,5 juta jiwa. 
Data di Semarang jumlah penderita diabetes pada tahun 2013 berjumlah 13.913 kasus dengan jumlah kematian 258. (Profil Kesehatan Kota Semarang Tahun 2013). Riskesdas (2013) terjadi peningkatan prevalensi DM di 17 propinsi seluruh Indonesia dari 1,1\% (2007) meningkat 2,1\% di tahun 2013. Dari total penduduk sebanyak 250 juta angka prevalensi kejadian DM salah satunya adalah propinsi Jawa Tengah dengan jumlah penderita DM tertinggi di kota Semarang sebanyak 509.319 jiwa. (profil Dinas Kesehatan Propinsi Jawa Tengah 2011)

Menurut Undang-undang Keperawatan No. 38 Pasal 19 Tahun 2014 terkait tentang izin perawat dalam melaksanakan praktek keperawatan. Praktek keperawatan tersebut dapat berupa klinik ataupun perawatan di rumah (home care). Home care adalah pelayanan kesehatan yang berkesinambungan dan komprehensif yang diberikan kepada individu dan keluarga di tempat tinggal mereka yang bertujuan untuk meningkatkan, mempertahankan atau memulihkan kesehatan atau memaksimalkan tingkat kemandirian dan meminimalkan akibat dari penyakit (Depkes, 2012).

Di Jawa Tengah sendiri telah banyak Rumah Sakit yang melakukan home care untuk kliennya, bahkan ada beberapa tenaga kesehatan yang melakukan praktek pelayanan kesehatan di rumah atau home care. Ada hampir 15 rumah sakit yang melakukan home care dan lebih dari 170 tenaga kesehatan yang berperan dalam home care (Survey Kompas, 2011).

Pelayanan kesehatan di rumah atau home care diantaranya perawatan pasien pascastroke, pasien pascaoperasi, dan perawatan luka. Persepsi keluarga terhadap luka diabetik didasarkan pada kondisi luka, opini lingkungan, serta manifestasi klinis ialah luka yang terjadi pada seseorang yang mempunyai gula darah tinggi, luka tersebut lama sembuhnya, semakin melebar jika tidak dirawat dengan baik, serta mengeluarkan cairan berwarna kuning kemerahan dan mengeluarkan bau yang tidak sedap.

\section{METODE}

Penelitian kualitatif di mana pengambilan data melalui teknik Focus Group Discussion (FGD) dan teknik wawancara mendalam (Indepth Interview). Uji validitas panduan wawancara dilakukan pada pasien ulkus diabetikum yang melakukan perawatan luka dengan jasa home care di Wilayah Kabupaten Semarang Jawa Tengah. Beberapa kriteria yang dipakai untuk memilih responden adalah sebagai berikut: 1) Pasien luka yang penyebabnya adalah karena diabetes militus 2) Grade luka minimal 3 berdasarkan wagner scale 3) Minimal perawatan di home care 3 bulan 4) Bertempat tinggal menetap di wilayah Kota Semarang. Uji kredibilitas pada penelitian ini dengan menggunakan triangulasi sumber yaitu pengambil kebijakan praktek mandiri perawat yaitu ketua organisasi profesi PPNI dan praktisi praktik mandiri perawat.

Pengambilan data dilakukan satu kali untuk FGD partisipan penderita ulkus diabetikum yang dilaksanakan 5 September 2015. Triangulasi praktisi praktek mandiri perawat tanggal 1 September 2015, sedangkan untuk organisasi profesi PPNI tanggal 15 September 2015. Jumlah Informan pada penelitian ini 6 penderita ulkus diabetikum dengan pengambilan data melalui FGD. Triangulasi menggunakan lebih dari satu metode pengumpulan data, dilakukan melalui wawancara rekaman audio, observasi fasilitas dan metode perawatan luka yang dikembangkan dalam praktek mandiri perawat. Pengumpulan data triangulasi sumber pada ketua organisasi PPNI sebagai pemberi rekomendasi ijin praktek dilakukan dengan Indept Interview.

Data dianalisis secara manual menggunakan metode "Analisis tematik". Tema-tema dihasilkan dari interpretasi dan eksplorasi berbagai pernyataan dan situasi, kemudian diberi kode warna, dipotong dan ditempel. Tema yang muncul dari catatan lapangan dimasukkan dalam analisis dan daftar tema gabungan dikembangkan untuk menunjukkan keterkaitan antar tema. 


\section{HASIL}

\section{Riwayat Tejadinya dan Lama Waktu Menderita Ulkus Diabetikum}

Penyebab terjadinya luka dikelompokkan menjadi dua penyebab yang pertama adalah karena trauma baik tidak disengaja maupun disengaja (proses operasi) seperti yang disampaikan partisipan ke-2 dan 6 berikut ini:

"30 Maret 2015 saya Post SC anak ke-3, seminggu masih basah, 2 minggu kemudian saya priksa lagi ke dokter bedah karena luka saya kok belum mengering"

"kejadian luka kaki ini awalnya waktu saya mancing kecocok (tertusuk benda tajam), terus ada lukanya 10 hari kemudian saya bawa ke romani terus saya diberi surat rujukan untuk ke kariadi, kurang lebih 16 hari saya dirawat di kariadi sampai saya mau diamputasi, setelah diamputasi saya selalu merasa kesakitan."

Penyebab ke dua adalah adanya gangguan pembuluh darah seperti yang disampaikan partisipan ke-1 berikut ini:

"awalnya ada gatal sedikit saya garukgaruk kok tambah parah, trus akhirnya saya bawa ke pengobatan macem-macem seperti di RS Telogorejo, di rumat, dr. Lewi hasil pemeriksaan dokter di RS Telogorejo dinyatakan ada sumbatan di pembuluh darah vena".

Waktu penyembuhan luka diabetes dapat dikategorikan menjadi tiga yang pertama dalam beberapa bulan, yang kedua penyembuhan 1-2 tahun dan yang ketiga lebih dari 10 tahun, seperti yang disampaikan partisipan partisipan 5,6 dan 3 berikut ini:

"Pertama itu 3 bulan terus sudah saya bawa ke dokter, malah semakin melebar dan semakin mendalam, ada keluar nanahnya juga, Saya rawat di tempat praktek perawat setiap 2 hari sekali selama 17 kali."
"Dari kecelakaan sampai sekarang sudah 2 tahun"

"kira-kira hampir 14 tahunan".

\section{Perawatan Luka Diabetes yang Baik Menurut Pemahaman Pasien}

Teknik perawatan luka yang dilakukan oleh perawat pada praktek mandiri perawat mengikuti perkembangan terkini dalam teknik perawatan luka. Berikut pernyataannya:

"Kalau di praktek saya perawatan luka, seperti yang sudah saya ikuti dalam pelatihan CWCC di Cirebon adalah perawatan luka yang melembapkan atau perawatan luka modern. Jadi ada beberapa cara yang nantinya akan diterapkan ke pasien luka untuk masing-masing perawatan lukanya. Untuk semua pasien yang datang ke saya selalu saya mempraktikkan teknik modern dressing baik pada pasien dari taraf ekonomi rendah sedang sampai menengah ke atas."

Seluruh partisipan belum memahami tentang perawatan luka yang sesuai dengan teori saat ini dengan menggunakan prinsip moist/lembab dan menggunakan produk modern dressing. Pemahaman partisipan tentang perawatan luka yang baik lebih ke arah proses teknik pembersihan luka Seperti pernyataan partisipan 1 dan 3 berikut ini:

"Ya kalau perawatan luka yang baik itu menurut saya ya harus telaten, memang tidak langsung cepet bisa sembuh, makanya perlu telaten dan sabar seperti di tempat praktek perawat.

"Dibersihkan dulu, nanahnya dibersihkan selanjutnya diberi obat dari luar lama-lama menjadi sembuh"

Perawatan luka yang baik juga dipahami partisipan sebagai tindakan yang mempunyai rasa empati perawat kepada pasien seperti pernyataan partisipan 6 sebagai berikut: 
"Bisa memenuhi permintaan pasien, harus konsekuen, harus bisa merasakan sakitnya pasien, bisa menuruti apa keinginan yang sakit, bertindak pelan-pelan supaya tidak ada rasa sakit, perawatnya bisa menerima keadaan pasien yang kesakitan".

\section{Pertama Kali Pasien Mengetahui tentang Perawat Praktek Mandiri}

Informasi tentang praktek mandiri perawat diketahui partisipan melalui 3 kategori yang pertama diketahui melalui papan praktek dan tulisan yang ditempel di depan tempat praktek mandiri perawat seperti pernyataan partisipan 5 berikut ini:

"setiap hari lewat depan sini lihat ada perawatan luka spesialis melalui plang praktek yang dipasang di depan dan tulisan di kaca depan"

Informasi kedua didapatkan dari orang lain baik keluarga, saudara, tetangga dan perawat praktek itu sendiri seperti pernyataan partisipan 2 berikut ini:

"adik saya Bu, dapat informasi dari adik saya kalau ada klinik perawatan luka di area Banyumanik"

\section{Jasa Pelayanan Home Care}

Home care merupakan bagian dari pelayanan praktek mandiri perawat selain praktek klinik keperawatan. Kunjungan rumah pada kegiatan home care dengan melakukan promotif, preventif, kuratif dan rehabilitative. Berikut pernyataan trianggulasi sumber ketua organisasi PPNI:

"Maka yang perlu ditata adalah bagaimana praktek itu betul-betul sesuai kewenangan dan kompetensi serta bentuk prakteknya karena akan berbeda. Ada praktek klinik keperawatan, ada home visit ada yang di home care, jadi di klinik keperawatan ada tindakan keperawatan, seperti wound care, hipnoterapi, akupresur, herbal, kemudian bekam, akan menjadi bidang garap perawat yang akan kita dorong ke depan menjadi bentuk praktek mandiri. Kemudian yang di home visit kan perawat harus banyak melakukan kunjungan rumah dan melakukan tindakan-tindakan baik promotif kuratif dan rehabilitatif, semua tindakan keperawatan itu bisa dilakukan di rumah termasuk tindakan home care. Itu harus kita dorong agar mereka bisa melayani tindakan promotif kuratif dan rehabilitatif selama 24 jam. Saya kira itu adalah bentuk-bentuk praktek yang harus kita kembangkan"

Seluruh partisipan memahami apa yang dimaksud dengan pelayanan home care secara penterjemahan dalam kalimat, untuk bentuk jasa yang diberikan hanya sebatas tahu dari pelayanan yang dilakukan oleh partisipan bersama praktisi praktek mandiri perawat seperti dinyatakan oleh partisipan 1 sebagai berikut:

"Perawatan yang bisa dipanggil untuk datang ke rumah yang diselenggarakan oleh perawat praktek atau biasa disebut klinik perawatan luka. Perawatan yang diberikan setahu saya ya perawatan luka sama mengukur tekanan darah dan mengecek gula darah, asam urat dan kolesterol".

\section{Alasan dan Keputusan Menggunakan Jasa Home Care}

Keputusan menggunakan jasa home care didasari oleh kebutuhan partisipan masing-masing, dari 6 partisipan sangat bervariatif yang mendasari keputusan itu. Pertama keputusan diambil dengan alasan kesulitan transportasi karena faktor usia sehingga tidak mampu menggunakan fasilitas mobil yang dimiliki seperti pernyataan partisipan 1 sebagai berikut:

"sudah gak ada yang nganter kemana-mana lagi. Kalau dulu saya masih bisa diantar suami ke RS untuk periksa, tapi sekarang sudah gak bisa, waktu muda bisa nyopir sekarang sudah tua ndak berani bu. Perawat juga stanby kok jika diundang sewaktu waktu”.

Keputusan lain dibuat karena kejenuhan proses pengobatan sebelumnya yang lama dan tidak adanya perubahan yang nyata pada 
proses penyembuhan luka seperti diungkapkan oleh partisipan 3 sebagai berikut:

"mpun pusing kaleh pengobatan sing teng dokter, teng $R S$, teng liyan-liyane niku memang mboten enten perubahan hasile lukane ajeg mawon, bareng dirawat ibu perawat perkembangane sae sanget, kulo seneng teng mriki kabeh dijelaske kanthi mudeng. perawatan teng nggene perawat kok cocok (sudah pusing dengan pengobatan ke dokter, ke rumah sakit, di tempat yang lainnya tidak ada perubahan hasil lukanya seperti itu terus, setelah dirawat sama ibu perawat perkembanganya baik sekali, saya senang di sini semua dijelaskan sampai mengerti. Perawatan di tempat perawat cocok"

Partisipan 2 mengambil keputusan menggunakan jasa home care karena melihat soft skill perawat sangat bagus dalam melayani pasien seperti pernyataannya sebagai berikut:

"perawat itu lebih telaten dan sabar, ramah dalam melayani pasien itu yang bikin ayem ati (hati nyaman), dan yang jelas saya tidak ngantri panjang Jadwalnya malah saya yang ngatur sesuai waktu longgar saya. kalau di RS ya harus ngantri kadang dokter tidak datang, kalau begitu waktu dah habis luka nggak terawat dengan baik mbak",

Budaya musyawarah mufakat dalam keluarga masih cukup kental di Indonesia sehingga ini juga terjadi pada dua partisipan yang menyatakan bahwa keputusan menggunakan jasa home care merupakan hasil keputusan dengan anggota keluarga seperti diungkapkan oleh partisipan 6 sebagai berikut:

"cerita ke anak saya dan setuju untuk ke sana. anak saya bilang "wis pak pokoke bar metu soko kene langsung prikso ning kono wae”, kalau membuka sakit, membukanya itu seenaknya tidak merasakan orang yang lagi sakit. saya nyari yang bisa memahami hati saya sakit"

\section{Keuntungan dan Kerugian Menggunakan Jasa Home Care}

Seluruh partisipan menyatakan bahwa kerugian menggunakan jasa home care tidak ada, sedangkan keuntungannya hampir seluruh partisipan menyampaikan terkait dengan perubahan kondisi luka yang semakin membaik selain itu juga disampaikan bahwa dampak psikologis yang positif karena diberi pelayanan dengan soft skill yang sangat baik oleh perawat, seperti diungkapkan oleh partisipan 2, 3, 5 dan 6:

"benten kaleh dokter teng RS liyane niku, perawatane sae, kulo remen, mantep teng mriki soale peribahan hasile lukane kulo cepet mantun. Kerugianne mboten wonten. (berbeda dengan dokter di rumah sakit yang lain perawatannya bagus, saya senang, mantap di sini soalnya hasil perubahan lukanya saya cepat sembuh. Kerugiannya tidak ada)"

"Keuntungannya tidak perlu repot ngatur jadwal. Perawatannya lebih sabar dan telaten, komunikatif apalagi ya banyak senyum pokoknya ramah banget bu. Waktu priksanya saya bisa atur sendiri jadi fleksibel. Ruginya sepertinya mboten wonten (tidak ada)"

“ kerugiannya tidak ada, keuntungannya kaki saya yang membusuk bisa sembuh sampai saya sekarang bisa kerja lagi. bisa cari uang lagi, sudah bisa jalan lagi sudah sembuh total"

"kesenangan saya dan ketenangan saya sipihak perawat menuruti keinginan saya yang sakit. balutannya minta begini-begini, nanti pasti saya akan dituruti. saya lebih tenang dan tidak merasa kesakitan, rugi koyone ora ono (rugi sepertinya ndak ada)"

\section{Perkembangan Luka Setelah Dirawat dengan Jasa Home Care}

Seluruh partisipan secara psikologis sangat puas dengan perkembangan luka yang dirawat dengan jasa home care secara fisik seluruh partisipan bisa mengevaluasi perubahan yang terjadi dari awal dating 
sampai perkembangan luka saat ini. Seperti diungkapkan oleh partisipan 1, 2, 3, 5 dan 6 sebagai berikut:

"Memang sakit sih saat dilakukan perawatan, Luka saya sudah membaik, kiri sudah banyak perubahan mengering, kanan kurang sedikit lagi, kadang masih suka merembes karena mungkin pola makan saya jelek”.

"Perkembangan yang saya rasakan banyak, Dulu waktu awal saya ke sini luka saya ada nanahnya ngrembes banyak. Warnanya masih memerah dan sakit, saya rutin perawatan di sini sekarang dah mulai banyak yang mengering, malah nanah sudah tidak ada lagi. Pengobatan kurang lebih 4 bulan berjalan baru ada perubahan, luka sudah mengering sedikit demi sedikit tapi masih ada rembesrembesnya, ada perubahan setelah dipegang perawat".

"kathah Bu perubahane, lukane kulo cepet mantun, kathah hasil perubahanne, Langsung enten perubahan, mantun sekedik-sekedik. seneng lan tambah mantep kulo. (banyak bu perubahanya luka saya cepat sembuh, banyak hasil perubahanya, langsung ada perubahan, sembuh sedikit-sedikit saya senang dan tambah mantap)".

"Luka saya itu pertama melebar begini (menunjuk di kaki) terus bau karena ada nanahnya sampai jari-jarinya diuklak-uklik sama mbak eni sampai tidak terasa. terus mbak eni nyuci luka saya sama air apa saya nggak tau, terus diguntingi, diureki sampai bersih ke dalam, membusuk bisa sembuh, sudah 3 bulan tidak bisa jalan, sekarang saya sudah bisa jalan lagi. Alhamdulillah lega seneng bisa kerja cari duit lagi (sambil tertawa)".

"di sini itu ada lubang sampai tembus ke balung (sambil menunjuk kakinya) tapi sekarang alhamdulillah sudah sembuh kurang lebih 4 bulan, sembuh total bisa pakai sepatu lagi untuk nutupi bekas lukanya mbak, kethok gagah to (kelihatan gagah ya)".

\section{PEMBAHASAN}

Semua partisipan mengetahui secara runtut riwayat terjadinya luka diabetes yang dialami, di mana hampir keseluruhan mengalami proses penyembuhan yang berbeda-beda ada yang langsung sembuh, kambuhan dan ada yang muncul luka kembali di kaki yang satunya.

Menurut Waspadji (2007) gangguan kaki diabetik terjadi karena kendali kadar gula yang tidak dilakukan dengan baik dan berlangsung terus-menerus selama bertahun-tahun. Penyebab utamanya adalah kerusakan syaraf (neuropati diabetik) dan gangguan pembuluh darah. Syaraf yang telah rusak membuat pasien diabetes tidak dapat merasakan sakit, panas, atau dingin pada tangan dan kaki. Di Indonesia terdapat 1785 penderita DM yang mengalami komplikasi neuropati $(63,5 \%)$, retinopati (42\%), nefropati (7,3\%), makrovaskuler (16\%), mikrovaskuler (6\%), luka kaki diabetic (15\%).

Teknik perawatan luka dengan menggunakan balutan yang bersifat lembab bertujuan untuk mempertahankan isolasi lingkungan luka yang tetap lembab. Kondisi luka yang dipertahankan tetap lembab akan membantu proses penyembuhan luka sebanyak $45 \%$ serta mengurangi komplikasi infeksi dan pertumbuhan jaringan residual. Perawatan luka bertujuan supaya luka menjadi sembuh serta mencegah dan mengatasi infeksi supaya tidak menyebar ke organ lain. Kematian akibat infeksi luka yang menyebar ke jantung tidak akan terjadi jika perawatan luka dilakukan sejak dini. Ada 7 faktor yang menghambat penyembuhan luka yaitu usia, infeksi, hipovolemi, hematoma, benda asing, iskemia, diabetes dan pengobatan (Cahyono, 2011).

Sebelum lahirnya Permenkes No. 148 Tahun 2010 dan Undang-undang No. 38 Tahun 2014 tentang Keperawatan, belum adanya aturan yang mengizinkan, membolehkan Perawat melakukan praktek mandiri di rumah. Sekitar tahun 2010 peraturan dan perundangan yang berlaku semakin jelas dan kuat bagi perawat yang ingin mendirikan praktek mandiri. Persyaratan izin praktek telah diatur 
sesuai peraturan dan perundangan yang berlaku di Republik Indonesia, agar masyarakat penerima pelayanan dan perawat sebagai pemberi layanan terlindung dari hukum yang berlaku. Undang-undang Keperawatan no 38 tahun 2014 disalah satu pasal mengatur tentang papan praktek perawat. jika Perawat ingin buka praktek mandiri, maka wajib mendirikan papan nama, apabila tidak memasang papan nama maka Perawat di anggap praktek ilegal (UU keperawatan no 38, 2014).

Praktek keperawatan dapat dilakukan di rumah sakit, klinik, puskesmas serta juga dapat dilakukan di rumah klien yang disebut dengan home care. Menurut American of Nurses Association (ANA) tahun 2012 pelayanan kesehatan di rumah (home care) adalah perpaduan perawatan kesehatan masyarakat dan keterampilan teknis yang terpilih dari perawat spesialis yang terdiri dari perawat komunitas, perawat gerontologi, perawat psikiatri, perawat maternitas dan perawat medikal bedah. Home care adalah pelayanan kesehatan yang dilakukan secara intensif dan berkelanjutan pada seseorang atau keluarga di tempat tinggal mereka sendiri, dilakukan oleh tenaga kesehatan profesional dengan perencanaan dan koordinasi yang diatur berdasarkan perjanjian bersama. Perawat adalah seorang profesi yang mandiri, perawat dituntut dapat memberikan pelayanan keperawatan yang profesional dan berkualitas kepada masyarakat. Berbagai jalan dapat dilakukan perawat untuk dapat menunjukkan hasil kerja dan kemampuannya kepada masyarakat (Karota, 2008).

Pelayanan home care memang dibutuhkan oleh masyarakat luas. Pasien dan keluarga menyatakan puas terhadap pelayanan home care RS Panti Rapih Yogyakarta dalam pemberian pendidikan kesehatan secara lengkap dan menyeluruh oleh perawat yang berkunjung. Hal ini menunjukkan bahwa kepuasan pasien tidak hanya dari segi pemberian pendidikan kesehatan saja namun juga dipengaruhi oleh beberapa hal diantaranya faktor kenyamanan dengan perawat, hubungan pasien dengan petugas RS dan biaya (Mulyanasari, 2014).
Kegiatan pelayanan kesehatan dalam home care adalah sebagai berikut: pelayanan medis, pelayanan dan asuhan keperawatan, pelayanan rehabilitasi medis, pelayanan gizi, kunjungan ibu hamil, kunjungan ibu bersalin, kunjungan bayi dengan risiko tinggi, pemasangan atau penggantian alat kesehatan misalnya selang lambung, catheter, tube pernapasan dan lain-lain, pengambilan praparat laboratorium tertentu, perawatan luka dan stoma, pemberian obat melalui muskuler dan intra vena, dan Pijat bayi (Karota, 2008).

Penelitian lain oleh Boekhorst, et al (2009) menyebutkan bahwa terdapat peningkatan kemajuan kesejahteraan hidup secara emosional dan tingkat kenyamanan nampak pada perawatan home care lansia di Panti Jompo jika dibandingkan dengan lansia yang dirawat di rumah pada umumnya. Sebagian besar lansia menyatakan lebih nyaman tinggal di Panti Jompo karena peran perawat yang tersedia 24 jam saat dibutuhkan. Berbeda dengan jika perawatan di rumah pada umumnya, karena keluarga kurang telaten dalam mengurus lansia. Perawat yang berada di Panti Jompo akan memberikan pelayanan kesehatan secara menyeluruh mulai dari memandikan dan pelayanan kesehatan untuk lansia terlebih dengan lansia berkebutuhan khusus (total care). Pelayanan kesehatan terkait penyakit penyerta seperti hipertensi, penyakit jantung dan DM juga dipantau rutin setiap hari.

Tujuan pelayan home care oleh tenaga kesehatan adalah: a) Meningkatkan, mempertahankan dan memperbaiki kondisi kesehatan pasien. b) Mencegah atau meminimalkan efek buruk penyakit untuk mencapai kemampuan pasien secara optimal. c) Meningkatkan penyembuhan dan penjagaan pasien. d) Meningkatkan pemahaman keluarga pasien tentang kesehatan karena dilibatkan dalam langkah pelayanan atau tindakan. e) Memenuhi kebutuhan atas rasa aman dan nyaman pasien karena berada ditengah-tengah keluarga dengan tetap memenuhi prinsip persyaratan kesehatan. f) Pelayanan akan cenderung lebih optimal dan tepat karena melihat kondisi sosio ekonomi dan budaya 
pasien yang dilayani. g) Meningkatkan efisiensi waktu, biaya, tenaga dan pikiran (Karota, 2008).

\section{SIMPULAN}

Tanggapan yang positif dari masyarakat pengguna pelayanan home care karena perawat memiliki pengetahuan, keterampilan dan sikap yang sesuai dengan kebutuhan stake holder serta melakukan pelayanan secara komprehensif. Peningkatan kemampuan perawat baik dari segi pengetahuan, keterampilan dan sikap perlu ditingkatkan dan dilakukan secara terusmenerus supaya bisa mengikuti perkembangan terkini dalam perawatan luka.

\section{SARAN}

Praktek mandiri perawat diperlukan adanya standarisasi pengaturan tentang pelaksanaan home care yang bisa digunakan sebagai rujukan untuk melakukan pelayanan yang standard serta bisa menjadi media profesi perawat untuk lebih dikenal dekat dengan masyarakat.

\section{KEPUSTAKAAN}

ADA (American Diabetes Association). 2013. Position Statement: Standar of Medical Care in Diabetes-2013. Diabetes Care, 33 (suppl.1): S11 diakses pada tanggal 22 Oktober 2013 dari http://www.care. diabetesjournals.org.

Peraturan Presiden Republik Indonesia No. 12 Tahun 2013. 2013. Tentang Jaminan Kesehatan. Jakarta: Presiden Republik Indonesia. Hal. 2

Cahyono, JB. Suharjo. 2011. Manajemen Ulkus Kaki Diabetik. Dexa Media Jurnal Kedokteran dan Farmasi.

Depkes. 2010. Peningkatan Jumlah Penderita Diabetes di Indonesia. <http;//www. depkes.go.id>

Dinas Kesehatan Kota Semarang. 2013. Profil Kesehatan Kota Semarang.
Karota, Evi. 2008. Perawatan Kesehatan di Rumah (Home Health Care). Jurnal Ilmiah.

Kementerian Kesehatan. 2010. Peraturan menteri kesehatan RI nomor 1796/ MENKES/PER/VIII/2011 tentang Registrasi Tenaga Kesehatan. Jakarta.

Kementerian Kesehatan. 2010. Peraturan Menteri Kesehatan RI nomor Hk.02.02/ MENKES/148/2010 tentang Ijin dan Penyelenggaraan Praktek Perawat. Jakarta.

Kemenkes. 2013. Riset Kesehatan Dasar (Riskesdas). Jakarta: Badan Penelitian dan Pengembangan Kementerian Kesehatan Republik Indonesia.

Mulyanasari, F., Subekti, H., \& Kep, S. 2014. Evaluasi Pelaksanaan Pendidikan Pasien dan Keluarga Pada Pelayanan Home Care Berstandar Joint Commission International Di Rumah Sakit Panti Rapih Yogyakarta (Doctoral Dissertation, Universitas Gadjah Mada). (Diunduh pada tanggal 7 Agustus 2015) Tersedia di http://etd.repository.ugm. ac.id/index.php?

Survey Kompas. 2011. (Diunduh pada 15 Februari 2015) tersedia di http;//www. kompas.com

Te Boekhorst, S., Depla, M. F., de Lange, J., Pot, A. M., \& Eefsting, J. A. 2009. The Effects of Group Living Homes on Older People with Dementia: A Comparison with Traditional Nursing Home Care. International Journal of Geriatric Psychiatry, 24(9), 970-978. (Diunduh pada tanggal 8 Juni 2015) Tersedia di http://www.readcube.com/ articles/

Undang-undang RI No. 38 tahun 2014 Tentang Keperawatan. (Diunduh pada 15 Februari 2015) tersedia di http;//www. UURI.go.id

Waspadji. S. 2007. Faktor Risiko Diabetes Mellitus. (Diunduh pada 15 Februari 2015) tersedia di http://www.medica. com/images/kabar.sehat.Edition 04.pdf. 